www.jmscr.igmpublication.org

Impact Factor 6.379

Index Copernicus Value: 71.58

ISSN (e)-2347-176x ISSN (p) 2455-0450

crossref DOI:_https://dx.doi.org/10.18535/jmscr/v6i3.205

Journal Of Medical Science And Clinical Research

IGM Publication

An Official Publication of IGM Publication

\title{
Quantification of Glaucomatous Field Defect in Primary Open Angle Glaucoma Patients at the time of Presentation: A Retrospective Cross- Sectional Study
}

\author{
Authors \\ Dr. Bhagyajyothi B.K ${ }^{1}$, Dr. Nilesh Kumar ${ }^{2}$, Dr. Niharika ${ }^{3}$ \\ JN Medical College.
}

\begin{abstract}
Introduction: Glaucoma is the leading cause of irreversible blindness across the world. Painless loss of vision often leads to delayed presentation, thus being known as the silent killer of vision. With advent of automated perimeters, it is now possible to analyse such visual field loss patterns and quantify it.

Aim: To quantify the visual field loss in cases of Primary open angle glaucoma at the time of first presentation

Settings: 1-year retrospective cross sectional study conducted at glaucoma clinic of a tertiary care hospital in Northern Karnataka

Results: 60 eyes of 60 patients were evaluated. Mean age of presentation was $63.63 \pm 9.81$ years. Most patients presented with severe field defect according to HAP criteria. Mean visual field loss at the time of presentation was $-13.47 \mathrm{~dB} \pm 9.80 \mathrm{~dB}$

Key-words: Glaucoma, POAG, VFA Defect, HFA
\end{abstract}

\section{Introduction}

Glaucoma is the 2nd leading cause of blindness worldwide, only behind cataract; and thus, is the leading cause of irreversible blindness. [1] There will be almost 80 million people in the world living with glaucoma by 2020 . The majority of these individuals will have open-angle glaucoma. With the disease having an ethnical predisposition, about $87 \%$ of these will be of Asian origin. [2] An estimated prevalence of Glaucoma in India in 2010 was 11.2 million, making it a medical and economic burden.
Glaucoma is widely and rightly regarded as "Silent Killer of Vision". Taking the analogy of Field of the vision given by Traquair, Glaucoma can be regarded as the rising sea level of blindness, and patient realizes the disease when the sea almost completely engulfs the island. This happens because the scotoma due to Glaucoma is a negative one, and also starts in the periphery; and thus, largely goes unnoticed, even in educated class. Patients with open-angle glaucoma usually have more severe loss as they don't have any 
warning signs like pain and redness, that is associated with closed angle glaucoma.

Primary Open Angle Glaucoma is associated with characteristic optic disc changes and visual field loss. Automated perimeters can analyze visual field loss by comparing to the general population, and they give the loss in terms mean deviation in decibels $(\mathrm{dB})$. There have been several studies that have reported the pattern of visual field loss and rate of progression of visual field loss. While it has been established that the visual loss field is quite advanced at the time of presentation, there had been only a few studies that have quantified that loss.

This study aims to quantify the visual loss in cases of Primary Open Angle Glaucoma (POAG) at the time of the first presentation to an ophthalmologist.

\section{Subjects and Methods}

This was a 1-year retrospective cross-sectional study conducted in the Glaucoma clinic of a tertiary care hospital in Northern Karnataka. All the newly diagnosed cases of Primary Open Angle Glaucoma, who had undergone Full-threshold 302 Humphrey's automated perimetry for visual field analysis, during January-December 2010 were enrolled. The patients with a history of color vision defects, refractive error (>5D spherical or $>2.5 \mathrm{D}$ cylindrical), amblyopia, dense cataracts, retinal pathologies, or on medications that can potentially affect optic nerve were excluded.

In cases of bilateral disease, the worse eye on perimetric evaluation was taken into consideration. The visual field defect was classified into No defect, Mild, Moderate, Advanced, Severe and End Stage Defect as per the Hodapp-Anderson-Parrish (HAP) criteria. (Table 1)

The data was collected and entered into MS Excel and was reported as percentages.

\section{Results}

60 eyes of 60 patients of POAG were enrolled in the study. Mean age at presentation was $63.63 \pm 9.81$ years, and no patient presented below 40 years of age. Out of the 60, $41(68.33 \%)$ patients were male and $19(31.67 \%)$ were female. 20 (33\%) patients had Diabetes, 31(51.66\%) patients had hypertension while $37(61.67 \%$ ) had a history of smoking present. 14(23.33\%) cases had a family history of glaucoma. (Table 2)

The patients were categorized into 6 groups depending on the HAP Criteria (Table 3), which were No defect, Mild, Moderate, Advanced, Severe and End Stage (When test couldn't be performed).

$30 \%$ of patients were showing No defect, $16.67 \%$ patients had Mild defect, $11.67 \%$ showed Moderate defect, Advanced defect was found in $5 \%$ while most of the patients presented with severe defect constituting $36.66 \%$ of the participants. No patient presented as end stage disease. (Chart 1)

The mean deviation at the time of presentation was found to be $-13.47 \mathrm{~dB} \pm 9.80 \mathrm{~dB}$ on visual field analysis done by Humphrey's field analyser using full threshold algorithm.

Table 1: Demography

Male: $41(68.33 \%)$

Female: $19(31.67 \%)$

Mean Age of Presentation: 63.63 \pm 9.81 years

\begin{tabular}{|c|c|c|}
\hline \multicolumn{2}{|l|}{ Table 2: Risk Factors } \\
\hline Factor & Present & Absent \\
\hline Family History & $23.33 \%$ & $76.66 \%$ \\
\hline Diabetes Miletus & $20 \%$ & $80 \%$ \\
\hline Hypertension & $51.66 \%$ & $48.33 \%$ \\
\hline Smoking & $61.67 \%$ & $38.33 \%$ \\
\hline
\end{tabular}




\begin{tabular}{|c|c|c|}
\hline Stage & $\begin{array}{l}\text { Humphrey } \\
\text { MD score }\end{array}$ & $\begin{array}{l}\text { Additional Criteria } \\
\text { at least } 1 \text { of the listed criteria must apply) }\end{array}$ \\
\hline \multicolumn{3}{|l|}{$\begin{array}{l}\text { Stage 0: } \\
\text { No or Minimal } \\
\text { Defect }\end{array}$} \\
\hline $\begin{array}{l}\text { Stage 1: } \\
\text { Early Defect }\end{array}$ & $\geq-6.00 \mathrm{~dB}$ & $\begin{array}{l}\text { - a cluster of } \geq 3 \text { points on the pattern deviation plot in an } \\
\text { expected location of the visual field depressed below the } 5 \% \\
\text { level, at least one of which is depressed below the } 1 \% \text { level } \\
\text { - CPSD/PSD significant at } \mathrm{P}<00.5 \\
\text { - } \quad \text { GHT Outside Normal Limits }\end{array}$ \\
\hline $\begin{array}{l}\text { Stage 2: } \\
\text { Moderate Defect }\end{array}$ & $\begin{array}{l}\geq-6.00 \text { to }- \\
12.00 \mathrm{~dB}\end{array}$ & $\begin{array}{l}\text { - } \geq 25 \% \text { but }<50 \% \text { of points on the attern deviation plot } \\
\text { depressed below the } 5 \% \text { level, and } \geq 15 \% \text { but }<25 \% \text { of points } \\
\text { deprese below the } 1 \% \text { level } \\
\text { at least } 1 \text { point within the central } 5^{\circ} \text { with sensitivity of }<15 \\
\text { dB but no points in the central } 5^{\circ} \text { with sensitivity of }<0 \mathrm{~dB} \\
\text { only } 1 \text { hemifield containing a point with sensitivity }<15 \mathrm{~dB} \\
\text { within } 5^{\circ} \text { of fixation }\end{array}$ \\
\hline $\begin{array}{l}\text { Stage 3: } \\
\text { Advanced Defect }\end{array}$ & $\begin{array}{l}\geq-12.01 \text { to }- \\
20.00 \mathrm{~dB}\end{array}$ & $\begin{array}{l}\text { - } \geq 50 \% \text { but }<75 \% \text { of points on pattern deviation plot } \\
\text { depressed below the } 5 \% \text { level and } \geq 25 \% \text { but }<50 \% \text { of points } \\
\text { depressed below the } 1 \% \text { level } \\
\text { - } \quad \text { any point within the central } 5^{\circ} \text { with sensitivity }<0 \mathrm{~dB} \\
\text { both hemifields containing a point(s) with sensitivity }<15 \mathrm{~dB} \\
\text { within } 5^{\circ} \text { of fixation }\end{array}$ \\
\hline $\begin{array}{l}\text { Stage 4: } \\
\text { Severe Defect }\end{array}$ & $\geq-20.00 \mathrm{~dB}$ & $\begin{array}{l}\text { - } \geq 75 \% \text { of points on pattern deviation plot depressed below the } \\
5 \% \text { level and } \geq 50 \% \text { but }<50 \% \text { of points depressed below the } \\
1 \% \text { level } \\
\text { - } \quad \text { at least } 50 \% \text { of points within the central } 5^{\circ} \text { with sensitivity }<0 \\
\text { dB } \\
\text { both hemifields containing }>50 \% \text { of points with sensitivity } \\
<15 \mathrm{~dB} \text { within } 5^{\circ} \text { of fixation }\end{array}$ \\
\hline $\begin{array}{l}\text { Stage 5: } \\
\text { End-Stage } \\
\text { Disease }\end{array}$ & & $\begin{array}{l}\text { Unable to perform HVFA in worst eye due to central scotoma or worst } \\
\text { eye VA } 6 / 60 \text { or worse due to POAG. Fellow eye may be at any stage }\end{array}$ \\
\hline
\end{tabular}

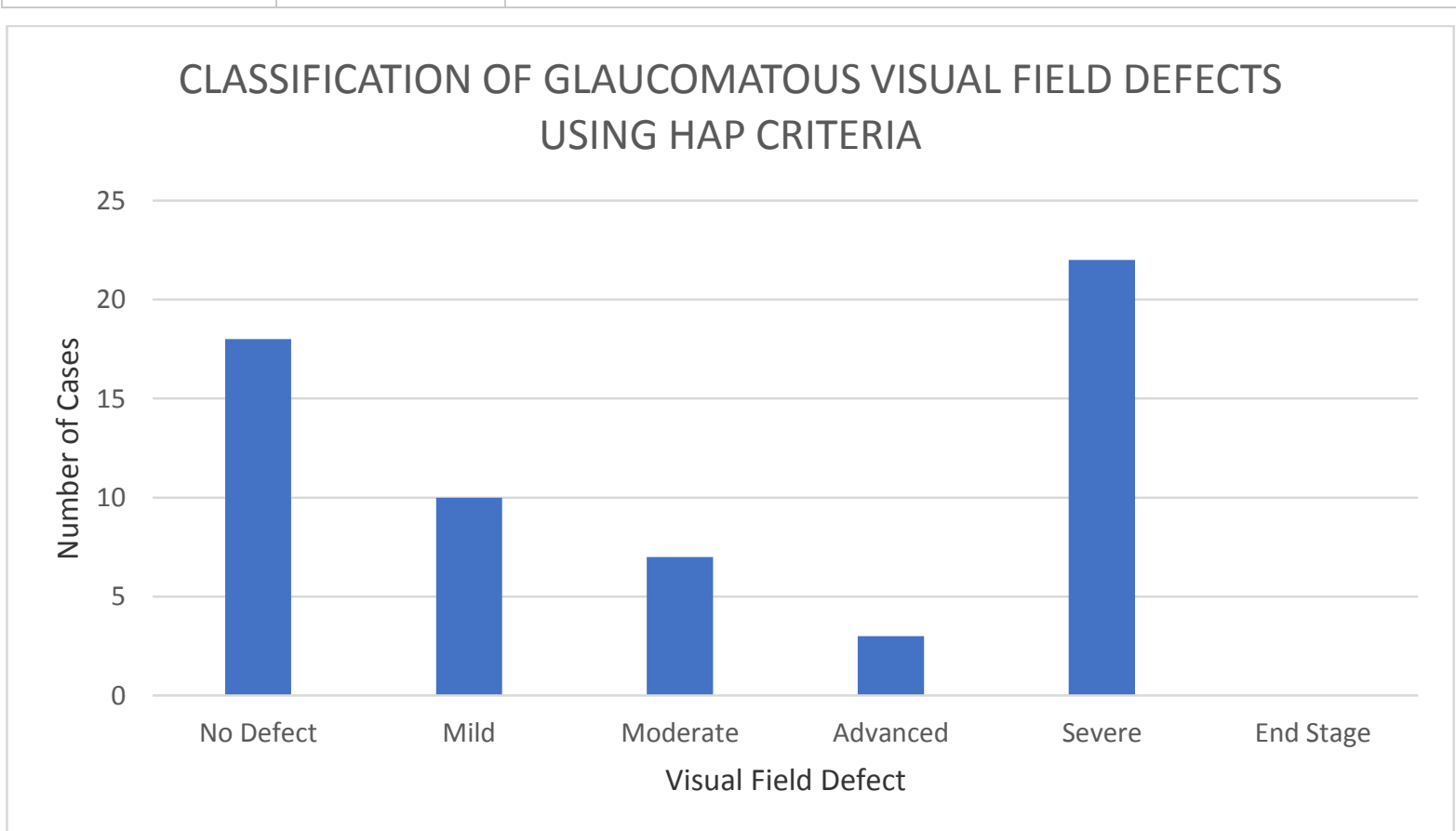

Chart 1: Visual Field Defects according to HAP Criteria 


\section{Discussion}

Visual field analysis and Optic nerve visualization are the critical components in the diagnosis of Glaucoma. Glaucoma then classically categorized into 2 groups depending on the gonioscopic appearance of anterior chamber angle, into Openangle and Closed-angle Glaucoma.

Glaucoma prevalence increases along the age till 6th to 7th decade, after which it falls. Prevalence of POAG in less than 40 years increased to 3 -folds in next decade i.e. 41-50 years, showed a study by Wilson M.R. [4] Suzuki et al reported the mean age of presentation of POAG patient as 63.8 years which co-related well with our study with the mean age being 63.63 years. [5]

Recent studies have come to prove that there are mutations in specific genetic loci associated with various types of glaucoma. WDR36 which is also known as GLC1G is found to be associated with POAG. These mutations tend to occur across generations and thus family history is now a proven risk factor for POAG. Kellerman et al reporting $13-25 \%$ of patients having a 1st-degree relative with the same disease. [6] $23.33 \%$ of the patients in our study had a family history. This underlines the magnitude of the problem, where despite positive family history and possible knowledge about the disease, the patients tend to present late in the disease. Our study showed that $35.7 \%$ of such cases had a severe loss.

Nutritional impairment can initiate Retinal Ganglion Cell loss, and thus any systemic disease with nutritional impairment can lead to glaucoma. Several epidemiological studies in this regard were controversial but a metanalysis by Zhao et al in 2017 found out that incidence of Glaucoma increases by $36 \%$ in patients with diabetes. [7] Also, diabetics have a tendency of having higher IOP and thus are more prone to have POAG, and Lin et al in 2010 reported that $30 \%$ patients of POAG are diabetes, which co-relates well with our study. [8]

Hypotension forms basis for one of the hypotheses for Normal tension glaucoma pathogenesis as it leads to low ocular perfusion pressure and high trans-laminar pressure, initiating glaucoma damage. Hypertension hampers the capillary circulation at the disc and is thought to make it more susceptible to damage in POAG. Blue mountain eye study, as well as EgnaNeumarktstudy, found out a positive correlation between Systemic hypertension and Open angle glaucoma. [9,10] Deb et al in 2014 found out that there is a 2-3 fold increase in glaucoma or glaucoma suspects in hypertensive population, and hypothesised that it may be due to bedtime dosing of anti-hypertensive medications that causes nocturnal drop in BP and causing lowperfusion pressure, which in turn causes glaucoma damage. [11] Lin et al reported 50.5\%, while JauDer et al reported $48.8 \%$ of the patients with POAG were having systemic hypertension, and we found similar presentation i.e. $51.66 \%$ in our study. [8,12]

Smoking increases levels of free radicals in circulation is a known risk factor for all neurodegenerative processes including POAG. Suzuki et al in 2008 found that $42.85 \%$ of the patients of POAG were smokers, and in our study, this percentage was found to be $61.67 \%$. [5] Though the mean age of presentation was 65.91 years among smokers and was later than nonsmokers which were 59.95 years, the severity of visual field loss at presentation was more among smokers; and the late presentation may be attributed to a general negligence towards health among the smokers.

Full threshold White on White perimetry is considered as the gold standard for visual field analysis, and form the basis of Hodapp-AndersonParrish (HAP) criteria to quantify the glaucomatous field defect and its prognosis. Our study has found out that patients with POAG at the time of presentation tend to have severe field defect, with a mean deviation of $-13.47 \mathrm{~dB}$, which emphasizes the position of POAG as the silent killer of vision. Regular fundus evaluation and visual fields examination after the age of 40 years is thus recommended to pick up early defects and initiate early therapy. 


\section{Conclusion}

This study emphasizes on the status of Glaucoma as the silent killer of vision, as demonstrated by high degree of visual field loss at first presentation. High degree of suspicion during clinical evaluation should be kept, and investigations should be carried out before ruling out glaucoma in suspected cases. We also recommend large scale screening camps to be organised to pick up asymptomatic cases in early stages of glaucoma.

\section{References}

1. Resnikoff S, Pascolini D, Etya'ale D et al. (2004) Global data on visual impairment in the year 2002. Bull World Health Organ 82:844-851

2. Quigley HA, Broman AT (2006) The number of people with glaucoma worldwide in 2010 and 2020. $\mathrm{Br} \mathrm{J}$ Ophthalmol 90:262-267

3. Hodapp E, Parrish RK, Anderson DR. Clinical decisions in glaucoma. St.Louis: Mosby; 1993.

4. Mason RP, Kosoko O, Wilson MR et al. (1989) National survey of the prevalence and risk factors of glaucoma in St. Lucia, West Indies. Part I. Prevalence findings. Ophthalmology 96:1363-1368

5. Suzuki Y, Iwase A, Araie M, Yamamoto $\mathrm{T}$, Abe H, Shirato $\mathrm{S}$, et al . Risk factors for Open - Angle Glaucoma in a Japanese population- The Tajimi Study. Ophthalmology. $2006 ; 113$ : 1613- 1617.

6. Kellerman L, Posner A : The value of heredity in the detection and study of glaucoma. Am J Ophthalmol . 1955 ; 40 : 681-684.

7. Zhou M, Wang W, Huang W, Zhang X. Diabetes Mellitus as a Risk Factor for Open-Angle Glaucoma: A Systematic Review and Meta-Analysis. Vavvas D, ed. PLoS ONE. 2014;9(8):e102972

8. Lin $\mathrm{HC}$, Chien $\mathrm{CW}, \mathrm{Hu} \mathrm{CC}$, Ho JD. Comparison of comorbid conditions between open- angle glaucoma patients and a control cohort : a case - control study. Ophthalmology. 2010 Nov ; 117 (11) : 2088-95.

9. Mitchell P, Lee AJ, Rochtchina E, Wang JJ. Open angle glaucoma and systemic hypertension: The blue mountains eye study. J Glaucoma 2004;13:319-26

10. Bonomi L, Marchini G, Marraffa M, Bernardi P, Morbio R, Varoto A. Vascular risk factors for primary open angle glaucoma: The Egna-Neumarkt Study. Ophthalmology 2000;107:1287-93

11. Deb AK, Kaliaperumal S, Rao VA, Sengupta S. Relationship between systemic hypertension, perfusion pressure and glaucoma: A comparative study in an adult Indian population. Indian $\mathrm{J}$ Ophthalmol2014;62:917-22

12. Ho JD, Hu CC, Lin HC. Open - Angle Glaucoma and the risk of stroke development : A 5- year population based follow-up study. Stroke. 2009 ; 40: 2685-2690. 